\title{
The relationship between snp-polymorphisms of the leptin gene and the development of fatty liver disease in dairy cows
}

\author{
Natalia $V$. Kovalyuk, Elena $V$. Kuzminova, Marina P. Semenenko*, Andrey A. Abramov, \\ and Ludmila I. Yakusheva
}

Krasnodar Research Center for Animal Husbandry and Veterinary Medicine, 350055 Krasnodar, Russian Federation

\begin{abstract}
This article shows the results of studies in the course of which in a comparative aspect the LEP polymorphism was studied in subpopulations of Holstein dairy cattle in cows with fatty hepatosis and in healthy animals. This is the first time such studies are being conducted. In this case, a hepothesis about the relationship of genetic markers, in particular the leptin gene, with the risk of developing and progression of fatty liver disease in a model of dairy cows when determining the frequency of occurrence of genotypes with LEP polymorphisms in groups of animals with hepatosis and healthy animals was studied. The aim of the research was to establish the possible influence of the genotype at the leptin locus (polymorphisms Y7F, A80V, R25C) on the frequency of occurrence of fatty hepatosis in dairy cows. In the course of studies on the $\mathrm{A} 80 \mathrm{~V}, \mathrm{R} 25 \mathrm{C}$, Y7F loci of the leptin gene, 180 cows were genotyped, where 80 animals were diagnosed with fatty hepatosis and 100 animals were healthy. In the group of healthy Holstein cows, compared with the group of animals with pathology, the RC genotypes (R25C polymorphism) were significantly more frequent, the frequency of the CC genotype (R25C polymorphism), on the contrary, was much higher in the group of animals with fatty hepatosis. Similar trends were noted for another polymorphism (A80V).
\end{abstract}

\section{Introduction}

Hepatosis is a term characterizing a number of pathologies of the hepatobiliary system, the main signs of which are dystrophic changes in the liver parenchyma, occurring without pronounced indicators of inflammation. Fatty liver disease (fatty hepatosis) over the past decades has become one of the most common forms of this organ damage throughout the world, both in humans and in animals. The incidence of hepatosis is from $10 \%$ to $30 \%$ in the general population of Europe, while among persons with obesity or diabetes mellitus, the incidence of pathology reaches $57-74 \%$. In highly productive cattle, fatty hepatosis is sometimes recorded up to half of the precedents of general gastroenterological pathology.

\footnotetext{
*Corresponding author: sever291@mail.ru
} 
The economic damage caused by the disease consists of a significant percentage of animal deaths, a decrease in milk production of cows (by 15-26\%), a decrease in body weight gain (by $10-15 \%$ ), culling of every 8-10 liver and deterioration in the quality of meat and milk [1-4].

Numerous studies have proven that the risk of hepatosis in a herd of high-yielding cows is largely connected with metabolic disorders associated with modern milk production technology. With a high level of lactation, the liver takes the greatest physiological load, realizing direct and indirect participation in all types of metabolism. Functional changes in its work lead to the occurrence of disorders, both in organ systems and in the body as a whole.

In cattle, regularities have already been identified between milk production and liver status in animals. For example, the consumption of feed at the beginning of lactation in cows in most cases lags behind the milk yield. As a result, in new-calf animals, especially in highly productive ones, in the first 6-10 weeks, an imbalance develops between the amount of energy consumption and nutrient compounds from the diet with their expenditure on physiological needs, primarily for milk synthesis. In response to this condition, an excessive loss of tissue reserves of the body occurs, which often leads to an imbalance in metabolic status and various pathologies (ketosis, liver diseases, etc.) [2, 5].

A feature of lactating cows is a high need for lipids in breast tissue. Lactation requires an increase in the synthesis and liver secretion of triacylglycerols, which are secreted into the blood in the form of lipoproteins, and if this function is impaired, they are deposited in the liver cells, resulting in lipid infiltration of the organ. Thus, if the secretion of triacylglycerols by the liver does not increase in proportion to their synthesis, then in cows liver lipid infiltration occurs and pathology as fatty hepatosis develops. In this aspect, the most problematic is the Holstein breed, since these cows have milk with the highest percentage of fat and high productivity [3].

In this connection, in order to preserve the health of the dairy cows, it is of prime importance to study the correlations between the milk productivity of animals, lipid metabolism and metabolic processes in hepatocytes, which makes it promising to study the polymorphisms of genes responsible for lipid metabolism and milk fat content in cows, as well as to assess their possible influence on the predisposition of individuals to the development of fatty hepatosis.

Leptin, a hormone produced by adipose tissue cells, plays an important role in metabolism, in particular, it regulates appetite and lipid metabolism in animals [6].

More than 60 SNP polymorphisms have been described for the leptin gene located in the 4 th chromosome in cattle. The gene structure is represented by a promoter region, 3 exons, 2 introns, and a 3'UTR area [7].

The leptin gene and its polymorphism have been studied in connection with energy metabolism in beef cattle, milk production [8-12] and fattening qualities [13] in Holstein animals. Chinese researchers were able to establish that a number of LEP polymorphisms are associated with body weight, heart girth, average daily gain, and body length in native Chinese cattle [14]. It has been shown that LEP polymorphism is associated with protein content [15], fat in milk, and ease of calving [6, 16]. In later studies, it was possible to establish a relationship between two LEP SNPs (g.-963C $>\mathrm{T}$ and c.357C $>\mathrm{T}$ ) with age at first calving, the frequency of pregnancy after the first calving, and the interval between calving [17].

It is possible that polymorphisms R25C, Y7F (located in exon 2), and A80V (located in exon 3 ) are associated with productive longevity $[10,18]$. Polymorphism of the leptin gene is associated with the content of somatic cells in milk [19], the characteristics of growth and development of livestock $[15,20]$. Interesting associations were found between the leptin gene polymorphism and the behavioral characteristics of livestock. Thus, Japanese 
scientists have established that the "wild" polymorphism of leptin can be useful for choosing cows with a calmer temperament [21].

We have previously genotyped 410 animals of the Holstein breed at loci Y7F, A80V, $\mathrm{R} 25 \mathrm{C}$ of the leptin gene and established the absence of allele polymorphism Y7F SNP (site $\mathrm{Y7F} A \rightarrow \mathrm{T}$ in position 95689996), as well as the fact that the VV genotype (site A80V) occurs in combination with the YYCC genotype (sites Y7F, R25C) in 100\% of the possible combinations of the YYRCVV, YYRRVV, YYCCVV genotypes. For SNP LEP - A80V in Holstein cattle, a low frequency of occurrence (0.07-0.09) of homozygous animals with the VV genotype was revealed, with a sufficiently high frequency of occurrence of heterozygous animals AV (0.43-0.45) [22].

The presence of diverse associations and a high degree of polymorphism of the locus indicate the important role of the leptin gene in the regulation of various metabolic processes in the body.

The purpose of the performed studies is an attempt to establish the relationship of the genotype to the leptin locus (polymorphisms Y7F, A80V, R25C) with the incidence of fatty hepatosis in dairy cows.

\section{Materials and methods}

In the course of studies using molecular biological methods 180 blood samples of Holstein cows were analyzed for leptin gene loci Y7F, A80V, R25C, 80 animals of which were comprehensively diagnosed with fatty liver disease and 100 animals were healthy.

Clinical experiments were carried out on dairy cows of the Holstein breed in the conditions of livestock farms in the Krasnodar Territory: "Khutorok" LLC, the educational and experimental farm "Kuban" and "Zemlya" LLC.

From the studied animals (500 heads), two groups were formed according to the principle of paired analogs. The first group $(n=80)$ was with signs of liver pathology by the type of fatty dystrophy and the second group $(n=100)$ contained only healthy livestock. The groups included cows ranked by physiological state (2-3 lactation, 6-12 weeks after calving), results of clinical examination, biochemical blood profile, as well as indicators of liver ultrasound diagnostics. The diagnosis of fatty hepatosis was made comprehensively on the basis of clinical and laboratory studies. The formation of groups was carried out as the animals arrived.

Blood samples were taken from cows from the tail vein after the morning milking. Biochemical blood tests were performed on a Vitalab Flexor Junior analyzer (an open system for photometric tests, manufactured by VitalScientific N. V. Netherlands) using reagents from ELITech ClinicalSystems (France) and Analyticon biotechnologies AG (Germany). The content of protein fractions and vitamins was determined in accordance with the "Methodological guidelines for the use of unified biochemical methods for examining blood, urine, milk in veterinary laboratories" (1981). At the same time, the level of lipid peroxidation processes and the antioxidant defense system of the cow's body were assessed in accordance with the methodological recommendations of of FSBRI "AllRussian Research Veterinary Institute of Pathology, Pharmacology and Therapy" (2010).

Ultrasound studies were performed using a PS-380V veterinary ultrasound scanner.

To isolate DNA from the blood of animals, we used Diatom TM DNA Prep 100 reagent kits from Izogen Laboratory, Moscow.

Genotyping for SNP sites R25C, Y7F, A80V was performed using PCR / RFLP [5]. PCR products were treated with appropriate endonucleases (Bsp13I, Bpu14I, PspEI) without preliminary purification. 
The actual frequency of occurrence of individual genotypes was determined by the ratio of the number of individuals carrying the genotype to the total number of individuals in the analyzed group.

Statistical processing of the results was carried out using ARCADA software, Microsoft Excel XP, and Statistical for Windows.

The reliability of the differences between the compared indicators was assessed according to the Student's test:

$$
t_{d}=\frac{\bar{X}_{1}-\bar{X}_{2}}{\sqrt{S \bar{x}_{1}^{2}+S \bar{x}_{2}^{2}}}
$$

where $t_{d}-$ difference validity criterion,

$\mathrm{X}_{1}$ и $\mathrm{X}_{2}-$ mean values of two compared groups,

$\mathrm{S} \bar{x}_{1}$ и $\mathrm{S} \bar{x}_{2}$ - errors of representativeness of mean values.

The correspondence between the observed and expected distribution of genotypes was checked by the chi-square method:

$$
\chi^{2}=\sum \frac{\left(H_{O}-H_{E}\right)^{2}}{H_{E}}
$$

where $\chi^{2}$ - conformity criterion,

$\mathrm{H}_{\mathrm{O}}-$ actual observation values,

$\mathrm{H}_{\mathrm{E}}-$ values of theoretical observations.

\section{Results and discussion}

The frequencies of occurrence of LEP polymorphisms at loci R25C, Y7F, and A80V in dairy cows selected for the experiment determined by the results of genotyping are shown in Table 1.

\begin{tabular}{|c|c|c|c|}
\hline \multirow{2}{*}{$\begin{array}{l}\text { SNP } \\
\text { LEP }\end{array}$} & \multirow[b]{2}{*}{$\begin{array}{l}\text { Genotype, } \\
\text { allele }\end{array}$} & \multicolumn{2}{|c|}{$\begin{array}{l}\text { Frequency of occurrence of alleles and genotypes } \\
\text { of leptin }\end{array}$} \\
\hline & & $\begin{array}{l}\text { in the group of dairy } \\
\text { cows diagnosed with } \\
\text { fatty hepatosis }(n=80)\end{array}$ & $\begin{array}{l}\text { in the group of } \\
\text { clinically healthy dairy } \\
\text { cows }(n=100)\end{array}$ \\
\hline \multirow{3}{*}{$\mathrm{R} 25 \mathrm{C}$} & RR & 0.12 & 0.16 \\
\hline & $\mathrm{CC}$ & 0.34 & 0.11 \\
\hline & $\mathrm{RC}$ & 0.54 & 0.73 \\
\hline \multirow{3}{*}{ Y7F } & YY & 1.00 & \\
\hline & $\mathrm{FF}$ & - & \\
\hline & YF & - & \\
\hline \multirow{3}{*}{$\mathrm{A} 80 \mathrm{~V}$} & AA & 0.46 & 0.58 \\
\hline & VV & 0.06 & - \\
\hline & AV & 0.48 & 0.42 \\
\hline
\end{tabular}

Table 1. Actual frequencies of LEP genotypes in selected groups of animals

Analysis of Table 1 shows that in the groups of Holstein breed cows there is no polymorphism at the Y7F locus, there is a deficiency of VV homozygotes at the A80V 
locus with a significant number of heterozygotes. This may indicate a reduced value for subpopulations of animals with the VV genotype.

In the group of healthy Holstein cows, compared with the group of animals with hepatopathology, the RC genotypes ( $25 \mathrm{C}$ polymorphism) were significantly $\left(\mathrm{x}^{2}=59.3\right)$ more frequent, the frequency of the CC genotype (R25C polymorphism), on the contrary, was much higher in the group of animals with fatty hepatosis. Similar trends were noted for another polymorphism (A80V). VV and AV genotypes were less common in healthy animals $\left(\mathrm{x}^{2}=9.1\right)$.

The regularities established by us earlier were confirmed: in cows of the Holstein breed $(\mathrm{n}=180)$ there is no polymorphism of SNP Y7F alleles, only complex LEP genotypes VVCCYY (SNP: R25C, Y7F, A80V) were also identified, although theoretically VVRCYY and VVRRYY genotypes should have been formed. In addition, the frequency of occurrence of the VV genotype (SNP A80V) is only 0.06, while the AV genotype occurs in the genotyped group of Holstein cattle with a frequency of 0.46 . Earlier, we suggested that the combination of complex genotypes YYRCVV and YYRRVV in Holstein cattle is not lethal at the embryonic level, but, probably, is impossible during the formation of a zygote. Whatever the reason for this phenomenon, it should be taken into account when selecting bulls for breeding.

\section{Conclusion}

The interest in breeding dairy cattle with increased disease resistance is global and genetic assessments of the development of progressive fatty liver disease would benefit from the additional information provided by genetic markers. With the further expansion of the selection of animals for genotyping, the obtained data will make it possible to identify molecular factors inherent in carriers of the risk genotype and form the possibility of developing a prognostic parameter for prevention of hepatopathies in veterinary medicine [23].

As the metabolic disease, fatty hepatosis has a multifactorial pathogenesis, therefore, apparently, it is impossible to identify any specific polymorphism that significantly affects the risk of its occurrence, and however, the results of the experiment prove that it makes sense to consider the leptin gene polymorphism in this connection.

Within the framework of solving fundamental problems of studying the molecular mechanisms of the development of hepatopathology, the gained knowledge about predictors of the prevention of hepatopathies will contribute to an increase in the safety of cattle (by reducing the death of cows due to liver diseases, calving safely and obtaining offspring with high resistance and viability from healthy animals).

The implementation of the research results at livestock enterprises will increase the efficiency of quality management and safety of livestock products by improving the potential of milk production of cows with an increase in the quality of milk.

\section{Acknowledgments}

The research was carried out with the financial support of the Russian Foundation for Basic Research and the Administration of the Krasnodar region, obtained as a result of a regional competition for fundamental scientific research to finance scientific project No. 19-416233016 r_mol_a "Study of the role of leptin gene polymorphism in the development of fatty hepatosis in cattle to identify predictors of prevention". 


\section{References}

1. Yu.N. Alekhin, Veterinary Medicine, 6, 6 (2011)

2. I.I. Kalyuzhny, N.D. Barinov, Bulletin of the Saratov State Agrarian University named after I.I. N.I. Vavilov, 8, 7 (2013)

3. R.A. Merzlenko, M.N. Zazdravnykh, V.V. Dronov, G.I. Gorshkov, Bulletin of the Kursk State Agricultural Academy, 6, 78 (2012)

4. M.P. Semenenko, E.V. Kuzminova, E.V. Tyapkina, V.A. Grin, A.A. Abramov, Methodical recommendations «Hepatosis in highly productive dairy cattle: diagnosis, treatment and prevention», 50 (2018)

5. A.I. Nikulin, G.I. Kopytina, Veterinary medicine, 1, 41 (2008)

6. J. Komisarek, Animal Science Papers and Reports, 10, 133 (2010)

7. D.H. Yoon, B.H. Cho, B.L. Park at al., J.Anim.Sci., 18(11), 1548 (2005)

8. P.J. Kononoff, P.J. Defoor, M.J. Engler at al., J Anim Sci., 95(1), 194 (2017)

9. J. Komisarek, J. Szyda, A. Michalak, Z. Dorynek, J. Anim. Feed Sci., 14, 491 (2005)

10. J. Szyda, J. Komisarek, J. Dairy Sci., 90, 2971 (2007)

11. A. Trakovická, N. Moravčíková, R. Kasarda, Acta Biochim Pol., 60(4), 783 (2013)

12. L. Fontanesi, D.C. Calò, G. Galimberti, R. Negrini, R. Marino, A. Nardone, Anim Genet., 45(4), 576 (2014)

13. S. Ardicli, H. Samli, B. Vatansever, B. Soyudal, D. Dincel, F. Balci, Arch Anim Breed., 62(1), 9 (2019)

14. W. Fu, N. Chen, S. Han, J. Huang, F. Li, R. Hao, H. Chen, C. Lei, Y. Ma, Reprod Domest Anim., 53(5), 1227 (2018)

15. J. Citek, M. Brzakova, L. Hanusova et al., Asian-Australas J Anim Sci., 34(1), $2(2020)$

16. L. Giblin, S. Butler, B. Kearney, S. Waters et. al., BMC Genetics, 11, 73 (2010)

17. K. Jecminkova, U. Müller, J. Kyselova, Z. Sztankoova, L. Zavadilova, M. Stipkova, I. Majzlik, Asian-Australas J Anim Sci., 31(11), 1721 (2018)

18. J. Szyda, M. Morek-Kopec, J. Komisarek, A. Zarnecki, BMC Genetics, 10, 12 (2011)

19. J. Metin Kiyici, B. Akyüz, M. Kaliber, K. ,Arslan, E.G. Aksel, M.U. Çinar, Anim Biotechnol., 23, 1 (2019)

20. J.D. Nkrumah, C. Li, J.B. Basarab, S. Guercio, Y. Meng, B. Murdoch et al., Can J Anim Sci., 84, 211 (2004)

21. S. Aierqing, A. Nakagawa, T. Bungo, J Adv Vet Anim Res., 7(1), 1 (2019)

22. N.V. Kovalyuk, V.F. Satsuk, E.V. Machulskaya, Yu.Yu. Shakhnazarova, Genetics, 12, $1(2018)$

23. N.V. Kovalyuk, L.I. Yakusheva, E.V. Kuzminova, E.V. Shiryaeva, A.A. Abramov, M.P. Semenenko,.Genetics and animal breeding, 3, 20 (2020) 